\title{
Whatever it Takes: A Close Examination of the Roles and Services Public Libraries Provide During Community Crises (Paper)
}

\begin{abstract}
Résumé:
This paper explores the roles and services public libraries provide during community crises. This is accomplished through a directed and summative content analysis of news articles concerning the services provided by public libraries during various crises. Seven roles and four adaptive capacities are closely examined, including how they have changed over time and whether or not they differ depending on the type of crisis, in order to attain a thorough understanding of the essential roles and services public libraries can offer to enhance their communities' resilience.
\end{abstract}

\section{Introduction}

Between 2009 and 2011 over 63\% of U.S. public library outlets were within a declared disaster county (Bishop \& Veil 2013, 40). Although public libraries have not been traditionally viewed as part of their communities' emergency management and response team, recent disasters have highlighted the beneficial roles public libraries can play in enhancing community resilience. ${ }^{1}$ In fact, the services public libraries provide have proved to be so crucial that the U.S. Federal Emergency Management Agency (FEMA) formally recognized public libraries as "essential services" during times of crisis in January 2011.

This paper explores, through a directed and summative content analysis of news articles concerning the services provided by public libraries during various crises, how these libraries are crossing boundaries and redefining their relationships with emergency responders to provide necessary and exceptional services during community crises.

\section{Background}

There have been three previous studies that have attempted to categorize the various roles and services public libraries take on during a community crisis. The first focused on identifying the roles of librarians during disasters (Featherstone, Lyon, \& Ruffin 2008), the second focused on identifying the service roles performed by hurricane-affected libraries (Brobst, Mandel, \& McClure 2012), and the third focused on the services provided by public libraries following a series of tornadoes and how those services enhanced the four adaptive capacities of community resilience: community competence, economic development, information and communication, and social capital (Veil \& Bishop 2014). Although each of these studies have made great strides 
towards improving our overall understanding of how public libraries can help enhance their communities' resilience following a disaster, there are some issues.

First, while the roles identified in the first study have been widely accepted, they do not pertain solely to public libraries. Out of the 23 librarians the researchers interviewed, only three were public librarians (Featherstone, Lyon, \& Ruffin 2008, 346). Second, while both the second and third studies focused on public libraries, their scopes were limited to a single type of natural disaster. Third, all of the studies stuck to the traditional definition of disasters as sudden or unforeseen events "which overwhelm local capacity to withstand, cope and recover; necessitating external assistance and involving various stakeholders" (Al-Dahash, Thayaparan, \& Kulatunga 2016, 1192). This means they have ignored smaller tragedies - for example, the deaths of five police officers ambushed on July 17, 2016 in Dallas, TX - that can also have a significant impact on communities. Thus, to gain a more thorough understanding of the essential roles and services public libraries can offer to help enhance their communities' resilience, this paper investigates how these libraries serve their communities during all types of community crises (i.e. natural, man-made, and health-related) both large and small.

\section{Methodology}

Due to the fact that the eight roles - collection managers, community supporters, educators and trainers, government partners, information community builders, information disseminators, institutional supporters, and internal planners - presented in the first study are already widely accepted within the library discipline, explore a broader range of crises, and can easily subsume the roles discovered during the second study, these roles served as the framework for this paper's initial directed content analysis (using manifest content). A second stage of directed content analysis (using latent content) was then done employing the opportunities for enhancing the four adaptive capacities as outlined by Veil and Bishop $(2014,728)$.

The content analyzed was a selection of news articles related to community crisis events between 2001 and 2017 in which public libraries provided services. ${ }^{2}$ These articles were primarily obtained through the NLM's Disaster Information Management Research Center's Librarians and Libraries Respond to Disasters: Bibliography on Library Roles in Disaster Preparedness, Response, and Recovery. Additional articles were obtained through a combination of keyword and Boolean searches within high yielding resources such as Library Journal. These searches resulted in 112 articles, which were placed in chronological order and then examined for public library specific data and repetition. This resulted in a final data set of 60 articles. $^{3}$

The articles were then analyzed by the author via directed content analysis using the above frameworks. Each community crisis incident was classified according to library, crisis type, event date, activities cited, and adaptive capacities demonstrated. Overall, this resulted in a total of 163 incidents being recorded for analysis within seven of the eight roles (see Table 1). ${ }^{4}$ 


\begin{tabular}{|l|c|c|}
\hline \multicolumn{2}{|c|}{ TABLE 1: Number of Incidents Per Role } \\
\hline \multicolumn{1}{|c|}{ Role } & Amount of Incidents & Percentage \\
\hline Collection Managers & 12 & 7.36 \\
\hline Community Supporters & 83 & 50.90 \\
\hline Educators and Trainers & 10 & 6.13 \\
\hline Government Partners & 15 & 9.20 \\
\hline Information Community Builders & 13 & 7.97 \\
\hline Information Disseminators & 22 & 13.49 \\
\hline Internal Planners & 8 & 4.90 \\
\hline
\end{tabular}

Once the incidents were established, a summative content analysis was used to explore how the roles and services provided by public libraries changed over time and whether or not they differed depending on the type of crisis.

\section{Findings}

\section{Quantitative Data}

Some of the key findings of this paper include:

- The role public libraries fulfill most is that of Community Supporters.

- The role of Government Partners seems to be assumed only during natural disaster crises.

- The only health-related crisis public libraries appear to be actively tackling is the opioid epidemic, which accounts for over $60 \%$ of the Internal Planner role.

- The adaptive capacities are fairly evenly distributed with the highest being community competence at $30 \%$ and the lowest being information and communication at $21.4 \%$. This is a significant change, as prior to FEMA's 2011 policy change, public libraries focused primarily on economic development.

\section{Qualitative Data}

In addition to the quantitative data this research supplied, qualitative data also revealed additional services that can fall under Collection Management, Community Supporters, Educators and Trainers, and Internal Planners roles. For example, there are several instances of public libraries curating collections based on the personal experiences and stories of community members surrounding a disaster (e.g. 9/11 and the Flint water contamination) as well as curating collections of the tributes left behind after a tragic community event (e.g. 2015 Charleston shooting, 2016 Orlando Pulse shooting, 2016 Dallas shooting). These new collections not only preserve the cultural impact for future generations and historians, they also provide a source of healing for the communities affected. Likewise additional opportunities for the four adaptive capacities were also revealed. 
The findings of this paper are noteworthy not only because they provide valuable examples of the various types of services public libraries can provide during community crises, but also because they reveal ways in which public libraries can contribute to their communities' resiliency. The skills and resourcefulness of librarians enable their communities to more easily cope with the impacts of community crises as well as adapt to and recover from the shocks caused by them. This is important to know for future practice and policy decisions as extreme weather events due to climate change become ever more common.

\section{Limitations}

It is worth noting that there are some inherent biases in the data. First, articles concerning more recent events such as Hurricanes Harvey and Irma, which occurred in late 2017 while this paper was being researched, were more easily located and therefore more prevalent. Second, articles concerning larger crises were also more prevalent. For instance, natural disasters were by far the largest percentage of crises recorded and of those hurricanes accounted for $69.3 \%$ with Hurricanes Katrina and Sandy making up just over half of that total when combined.

\section{Conclusion}

Overall, this paper demonstrates that when it comes to the roles and services public libraries provide during a community crisis, what they lack in formal policy ${ }^{5}$ they more than make up for in creativity and ingenuity by crossing boundaries and doing whatever it takes to meet their communities' needs.

\section{Endnotes:}

1. For the purposes of this paper community resilience refers to the collective ability of a geographically defined area "to absorb the impacts of external and internal system shocks without losing the ability to function, and failing that, to cope, adapt, and recover from those shocks" (Tierney 2004, p. 6).

2. News articles were chosen for this study in view of the fact that the media often plays a critical role in shaping public opinions regarding disaster response and recovery efforts (Cox, Long, Jones, \& Handler 2008, p. 470). It is therefore worth noting which services they choose to highlight and which they do not (Huckin 2002).

3. Originally, this paper also sought to compare the differences in responses between Canadian and U.S. public libraries, so searches for Canadian public libraries responding to community crises were also conducted. However, these searches produced only six articles; two of which, when examined, did not fit the necessary criteria. Thus, given this statistically insignificant representation, only articles related to U.S. public libraries were analyzed.

4. The role of institutional supporter was found to be non-existent within public libraries, though it is possible that public library associations like the American Library Association (ALA), which were not examined for the purposes of this paper, could fit this role. Further study is needed.

5. A 2005 a Heritage Preservation survey found that $78 \%$ of libraries have no local disaster plan (Oelschlegel, 2008), which indicates a distinct need for clearer policies and procedures regarding how public libraries can and should prepare for crises within their communities. 


\section{Reference List:}

Al-Dahash, H., Thayaparan, M., \& Kulatunga, U. (2016). Understanding the terminologies: Disaster, crisis and emergency. In P.W. Chan and C.J. Neilson (Eds.) Proceedings of the $32^{\text {nd }}$ Annual ARCOM Conference, 5-7th September, Manchester, UK, Association of Researchers in Construction Management, Vol. 2, 1191-1200.

Bishop, B. W. \& Veil, S. R. (2013). Public libraries as post-crisis information hubs. Public Library Quarterly, 32(1), 33-45. doi:10.1080/01616846.2013.760390

Brobst, J. L., Mandel, L. H., \& McClure C. R. (2012). Public libraries and crisis management: Roles of public libraries in hurricane/disaster preparedness and response. In C. Hagar (Ed.), Crisis information management: Communication and technologies (pp. 155-173). Oxford, UK: Chandos Publishing.

Cox, R. S., Long, B. C., Jones, M. I., \& Handler, R. J. (2008). Sequestering of suffering: Critical discourse analysis of natural disaster media coverage. Journal of Health Psychology, 13(4), 469-480. doi:10.1177/1359105308088518

Featherstone, R.M., Lyon, B.J., \& Ruffin, A.B. (2008, October). Library roles in disaster response: an oral history project by the National Library of Medicine. Journal of the Medical Library Association, 96(4), 343-350. doi:10.3163/1536-5050.96.4.009

Huckin, T. (2002). Textual silence and the discourse of homelessness. Discourse \& Society, 13(3), 347372. doi:10.1177/0957926502013003054

Oelschlegel, S. (2008). Emergency preparedness and the role of information services. Tennessee Libraries, 58(1). Retrieved from https://www.tnla.org/page/215?dues

Tierney, K. (2014). The social roots of risk: Producing disasters, promoting resilience. Stanford, CA: Stanford University Press.

Veil, S. R. \& Bishop, B. (2014). Opportunities and challenges for public libraries to enhance community resilience. Risk Analysis, 34(4), 721-732. doi:10.1111/risa.12130 